\title{
The Factors Associated with the Delayed First Antenatal Care in the Philippines
}

\author{
Hanna Horiguchi", Minato Nakazawa \\ Department of International Health, Graduate School of Health Sciences, Kobe University, Japan
}

Copyright $(2018$ by authors, all rights reserved. Authors agree that this article remains permanently open access under the terms of the Creative Commons Attribution License 4.0 International License

\begin{abstract}
The maternal mortality ratio has decreased in many countries since 2000 , but in the republic of the Philippines. World Health Organization recommends that the standards of antenatal care (ANC) should start as early as possible in the first trimester, while only $63.4 \%$ of pregnant women began the ANC within the first trimester. This study aimed to clarify socio-economic status and current situation regarding pregnancy, and to explore the factors associated with the timing of the first ANC in Leyte by comparing the women who took first ANC within first trimester (early ANC group) with the women whose first ANC delayed after 4 months of pregnancy (late ANC group). We visited 108 women who had pregnancy experience by opportunistic sampling and conducted the semi-structured interview. The early ANC group and the late ANC group were 76 and 27 respectively. Only one person did not take any ANC and 4 people did not remember the timing of first ANC. Monthly income and consultation with husband significantly differed between 2 groups. Around 15\% women did not have accurate knowledge about determining pregnancy. In conclusion, it is necessary to spread the right and practical information about pregnancy and antenatal care in the community.
\end{abstract}

Keywords Timing of First Antenatal Care, Exploratory Study, Semi-structured Interview, the Republic of the Philippines

\section{Introduction}

Since 2000, many countries have tried to accomplish millennium development goals (MDGs). Owing to this effort, the maternal mortality ratio (MMR) in the whole world have successfully fallen by 44\% from 385 in 1990 to 216 in 2015 as stated in the final report for MDGs. The annual number of maternal deaths also decreased by $43 \%$ approximately from 532000 in 1990 to 303000 in 2015 [1]. Despite this great achievement, the speeds of these progresses were slower than expected and still approximately 830 women are dying due to pregnancy related causes every day in the world. Thus, the goal of reducing MMR has continued as one of the targets in the Sustainable Development Goals (SDGs) towards ending preventable maternal death. Among the trends in maternal mortality ratio given for WHO Western Pacific Region countries by UNICEF from 1990 to 2015, the republic of the Philippines (hereafter the Philippines) has remained high since 1990 and efforts must be continuously made to accomplish the SDGs in the next 15 years [1].

According to the result of national demographic and health survey (NDHS) 2013, more than $80 \%$ of women visited $\mathrm{ANC}$ at least four times during their pregnancy periods. However, roughly $40 \%$ of pregnant women visited first ANC after four months of their gestation periods [2]. The specialists of World Health Organization recently announced new recommendation for ANC to replace the four-visit focused ANC (FANC) model in 2016; WHO recommendations on antenatal care for a positive pregnancy experience [3]. This new guideline changed the recommended schedule to health providers during pregnancy period for preventing perinatal mortality and promoting women's experience of care. The 2016 WHO ANC model recommended at least eight ANC contacts scheduled the first up to 12 weeks of pregnancy, the second in 20 weeks, the third in 26 weeks, the fourth in 30 weeks, the fifth in 34 weeks, the sixth in 36 weeks, the seventh in 38 weeks and the last in 40 weeks. At the same time, it emphasized the quality of ANC contacts as well as the schedule for increasing the number of pregnant women to fulfill the requirements [3]. To increase the number of ANC visits more than the current situation and improve maternal and neonatal conditions in the Philippines, the early access to ANC may be effective.

In the present study, I focused on the Leyte province because of its special feature. What makes Leyte province special? First of all, the report from the national statistics office of the Philippines revealed the annual per capita relative poverty threshold 2015 in Leyte was 20,807PHP, so that the monthly threshold was calculated as around 1,734 PHP [4]. It's less level of the absolute poverty line in revised MDGs as 1.75 USD ( $\fallingdotseq 77.4$ PHP) per day (calculated as $100 \mathrm{PHP}=\$ 2.26$ Jan 2015). The poverty incidence among Population was estimated as $31.0 \%$ in 
Leyte, $21.6 \%$ in the Philippines. Secondly, the Project for Strengthening Maternal and Child Health Services in Eastern Visayas was held by Japanese International Cooperation Agency (JICA) during 2010 - 2014 and this project sites have spread over whole Leyte provinces [5]. Thirdly, since 2012, a law prohibiting home delivery has been adopted and implemented by the Provincial Government of Leyte. Traditional birth attendants still exist there, but they are prohibited to help delivery any more. If pregnant women delivered at home, they will be fined 800 pesos (about 15.5 USD). Lastly, the MMR in the eastern Visayas which includes Leyte province has been recorded quite higher number than the other regions since 1976 [6]. This higher MMR remained in 2013, even the province and many organizations have worked hard for improving the situation there for a long time. Leyte province can be regarded as one of the high-risk regions of maternal death in the Philippines. However, until now, there is still no study about the reasons why pregnant women don't attend their 1st ANC within the first trimester there.

\section{Objectives}

Based on the above consideration, this study aims to clarify socio-economic status (SES) and current situation regarding pregnancy and $\mathrm{ANC}$, and to explore the factors associated with the delayed first ANC in Cabuynan, Tanauan Leyte.

\section{Materials and Methods}

\subsection{Study Area}

This study was conducted in the barangay of Cabuynan (total population was 3,350 in August 1, 2015 [7]), municipality of Tanauan, Leyte province, the Philippines. Cabuynan is located approximately 18 kilometers south of Tacloban city which serves as the regional center of the Eastern Visaya. The basic statistical data were shown below (table 1 [8]).

\subsection{Study Participants and Data Collection}

The 108 participants were chosen by opportunistic sampling: The first author visited house by house and conducted interviews if approved after getting informed consent. The interviews using a semi-structured questionnaire (table 2) were conducted by research assistants who could communicate with them in Waray language which is the primary language. The study period was from $2^{\text {nd }}-26^{\text {th }}$ June in 2016. The questionnaire was developed by the first author based on NDHS 2013. The questionnaire included SES, demographic information, reproductive history, detailed information during the latest pregnancy and delivery such as the number of ANC, the timing of $1 \mathrm{st}$ ANC, the type and place of delivery and so on.

\subsection{Analysis}

The subjects were categorized into the two groups: "the early ANC group" who took first ANC within three months and "the late ANC group" who took the first ANC after four months of pregnancy period. During this process, 5 women's data were excluded for the reason one woman didn't take any ANC during her pregnancy and 4 women could not answer the timing of their 1st ANC.

For comparison, categorical data were analyzed using Fisher's exact test and Cochran-Armitage test in the cases that any trend can be supposed. Quantitative data were compared by Mann-Whitney $U$ test. All statistical analyses were done by $\mathrm{R}$ software version 3.3.1[9] with EZR package version 1.33[10].

\subsection{Ethical Considerations}

This study was ethically approved by the ethics committee of Kobe University Graduate School of Health Sciences 468-1. Prior to the interview, we received informed consent from the all respondents

Table 1. Basic information about Leyte province [8]

\begin{tabular}{|c|c|c|c|}
\hline Total population & $1,724,679$ & Elderly population (60 years old and over) & 252,907 (14.7\%) \\
\hline Male & $889,054(51.5 \%)$ & $\begin{array}{c}\text { Highest educational attainment (Household } \\
\text { population by 5 years old and over) }\end{array}$ & No grade completed \\
\hline Female & $835,625(48.5 \%)$ & Elementary undergraduate & $140,649(9.2 \%)$ \\
\hline $\begin{array}{c}\text { Marital status (Household population } \\
\text { 10 years old and over) }\end{array}$ & & Elementary graduate \\
\hline Single & $573,681(43.2 \%)$ & High school undergraduate \\
\hline Married & $470,220(35.4 \%)$ & High school graduate & $200,812(13.1 \%)$ \\
\hline Widowed & $66,119(5.0 \%)$ & College undergraduate & $249,820(16.3 \%)$ \\
\hline Divorced/Separated & $21,306(1.6 \%)$ & Academic degree holder \\
\hline Common-Law/Live-in & $196,184(14.8 \%)$ & Others & $118,864(7.8 \%)$ \\
\hline Unknown/Not Stated & $69(0.0 \%)$ & $121,310(7.9 \%)$ \\
\hline
\end{tabular}


Table 2. The list of questions

\begin{tabular}{|c|c|}
\hline No. & Question \\
\hline 1. & When is your birthday? \\
\hline 2. & Do you believe any religion? \\
\hline 3. & How long did you go to school? \\
\hline 4. & $\begin{array}{l}\text { Where is your home town? Different island } \rightarrow \text { What did you bring } \\
\text { here? }\end{array}$ \\
\hline 5. & Who do you live together? \\
\hline 6. & Your job \\
\hline 7. & Family income (all income which you share with your family) \\
\hline 8. & How much do you usually spend money for daily life? \\
\hline 9. & $\begin{array}{l}\text { How about your family's economic state? Why? } \\
\text { E.g. Don't have money, compare to others... } \\
\end{array}$ \\
\hline 10. & $\begin{array}{l}\text { Do you have health insurance? What type of health insurance do } \\
\text { you have? }\end{array}$ \\
\hline 11. & Do you have any communication tool? \\
\hline 12. & What do you usually do using communication tool? How often? \\
\hline 13. & How many children do you want? Why? \\
\hline 14. & Date of birth (day/month/year) \\
\hline 15. & Weight at birth \\
\hline 16. & Height at birth \\
\hline 17. & Style of delivery \\
\hline 18. & Do you have mother and child book? \\
\hline 19. & When and how do you realize about pregnant? \\
\hline 20. & How many times did you take checkups during pregnancy period? \\
\hline 21. & When did you take these checkups? \\
\hline 22. & Are there any problems during delivery? \\
\hline 23. & Did you have any problems after delivery? \\
\hline 24. & $\begin{array}{l}\text { Who and what did you consult when you have any health problem } \\
\text { related to your pregnancy? }\end{array}$ \\
\hline
\end{tabular}

\section{Results}

\subsection{The Awareness of and Attitude toward ANC}

Almost all participants (99.0\%) took at least one ANC during their last pregnancy except one. Ninety-two women $(89.3 \%)$ took ANC more than 4 times which were the recommended number of ANC by WHO. Moreover, all of them answered 'YES' when we asked the question whether they wanted to take ANC during their pregnancy or not. Seventy-six subjects $(72.8 \%)$ were the early ANC group and 27 subjects $(27.2 \%)$ were late ANC group.

\subsection{Demographic Data and Socio-economic Status (SES)}

As table 3 indicates, there was no significant difference in family type, educational level, job, insurance, year nor age of delivery between the 2 groups of timings of $1^{\text {st }}$ ANC. It was obvious that almost all subjects lived under the monthly per capita relative poverty threshold 2015 in Leyte which was shown by the dotted line with the income of around 1,734 Philippine pesos (figure 1). And except two people, all of them lived in under absolute poverty which was illustrated by solid line. Comparing two groups, the early ANC group was slightly richer than the late ANC group, but the variance was quite large. When we asked about that they regarded their economic status as poor, middle, or rich stage, 79 women $(76.7 \%)$ stated poor. The early ANC group had three children on average which was one child less than the late ANC group

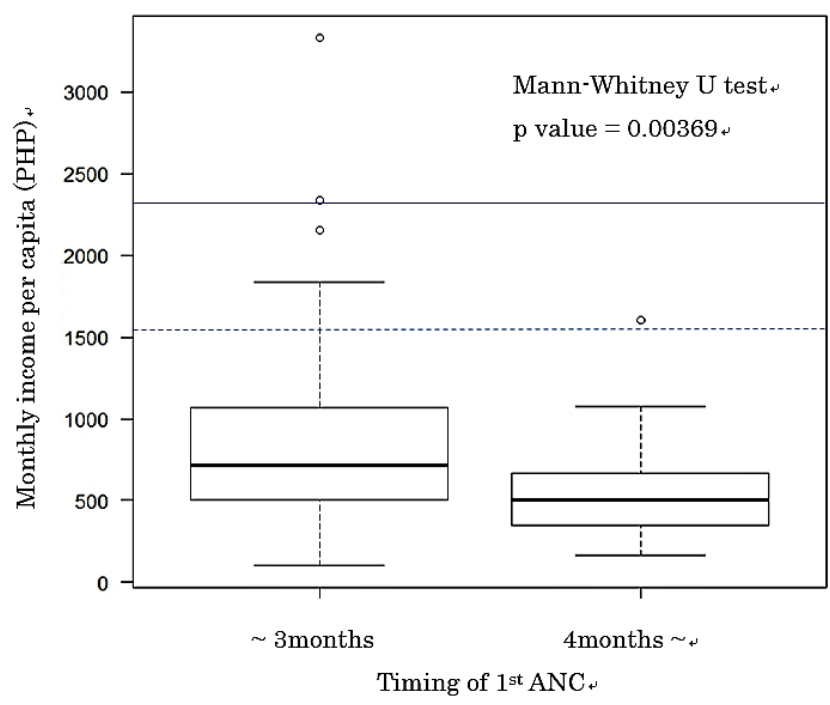

Figure 1. Comparison of monthly income between the two ANC groups

Table 3. Demographic data and socio-economic status

\begin{tabular}{|c|c|c|c|}
\hline & the timin & g of 1st ANC & \\
\hline & $\begin{array}{c}\sim 3 \text { months } \\
(n=76)\end{array}$ & $\begin{array}{c}4 \text { months } ~ \\
(n=27)\end{array}$ & $p$ value \\
\hline Family type & & & 0.4288 \\
\hline Nuclear & $60(78.9 \%)$ & $19(70.4 \%)$ & \\
\hline Others & $16(21.1 \%)$ & $8(29.6 \%)$ & \\
\hline Education & & & 0.178 \\
\hline$\sim$ Elementary & $11(14.5 \%)$ & $8(29.6 \%)$ & \\
\hline Junior & $50(65.8 \%)$ & $13(48.1 \%)$ & \\
\hline High & $15(19.7 \%)$ & $6(22.2 \%)$ & \\
\hline Job & & & 0.735 \\
\hline Housewife & $58(76.3 \%)$ & $21(77.8 \%)$ & \\
\hline Sari-Sari store & $12(15.8 \%)$ & $3(11.1 \%)$ & \\
\hline Others & $6(7.9 \%)$ & $3(11.1 \%)$ & \\
\hline Insurance & & & 0.2492 \\
\hline Do not have & $30(39.5 \%)$ & $9(33.3 \%)$ & \\
\hline Expired & $6(7.9 \%)$ & $0(0.0 \%)$ & \\
\hline Have & $40(52.6 \%)$ & $18(66.7 \%)$ & \\
\hline Year of delivery & & & 0.4257 \\
\hline$\sim 2001$ & $13(17.1 \%)$ & $4(14.8 \%)$ & \\
\hline $2002 \sim 2006$ & $8(10.5 \%)$ & $2(7.4 \%)$ & \\
\hline $2007 \sim 2011$ & $11(14.5 \%)$ & $8(29.6 \%)$ & \\
\hline $2012 \sim 2016$ & $44(57.9 \%)$ & $13(48.1 \%)$ & \\
\hline Mother's age at the delivery & & & 0.875 \\
\hline Adolescent & $6(7.9 \%)$ & $2(7.4 \%)$ & \\
\hline Middle & $50(65.8 \%)$ & $16(59.3 \%)$ & \\
\hline Advanced & $20(26.3 \%)$ & $9(33.3 \%)$ & \\
\hline
\end{tabular}

\subsection{Triggers for Awareness of Their Pregnancy}

The factors which made subjects aware of their pregnancy were dizziness, morning sickness, headache, pregnancy test, and amenorrhea. The timings of awareness were not significantly different by those factors. Interestingly, almost $100 \%$ of the participants recognized 
their pregnancy when their menstruation was delayed, although the timing of recognition varied from one month to five months. As it was expected, the early ANC group showed earlier recognition of their pregnancy.

\subsection{Pregnancy Test}

Among 34 people used pregnancy test for the last pregnancy, 30 subjects $(88.2 \%)$ wanted to use it for the next time. Only four people didn't want to use it for their next pregnancy even if they used it before. Within 41 women who didn't want to use it for the opportunity, 30 of them answered the reason why they didn't want to use: 12 subjects (40.0\%) testified and gave clear statement about the signs of pregnancy, 7 subjects $(23.3 \%)$ wanted to be surprised, 4 subjects $(13.3 \%)$ for the reason of saving money and 7 subjects for the other reasons. Moreover, the proportion of pregnancy test use was not significantly different between the two ANC groups.

\subsection{Consultation during Pregnancy}

Almost half of the subjects have consulted with their husband about the problems whatever accidents happened during their pregnancy period and the proportion of the early ANC group was significantly larger in the women who consulted with husbands than in the women who didn't (table 4).

Table 4. Consultation to husband during pregnancy

\begin{tabular}{|cccc|}
\hline & \multicolumn{2}{c}{ Timing of 1 st ANC } & Fisher's exact test \\
& $\sim 3$ months & 4months & value \\
\hline Yes & $42(55.3 \%)$ & $8(29.6 \%)$ & 0.026 \\
No & $34(44.7 \%)$ & $19(70.4 \%)$ & \\
\hline
\end{tabular}

\subsection{The Reason of Delayed ANC Visit}

Among the 27 late ANC group, 12 subjects (44.4\%) were aware of their pregnancy after one or two month(s) delay of their menstruation period. Fourteen subjects (51.9\%) took 1st ANC more than 2 months after their first awareness of pregnancy. Among them, Multipara represented about $78.6 \%$ and all of primiparas were under 26 years old. Seven of them mentioned reasons why they delayed taking their 1st ANCs even though they could realize early in their pregnancy period: There were four reasons such as "I was too shy to tell my family because I was too young to have a baby", "I was too busy", "my neighbors do just like that" and "I was thinking" (Table 5).

Table 5. Consultation to husband during pregnancy

\begin{tabular}{|ccccc|}
\hline Reason & $\begin{array}{c}\text { The age (year) } \\
\text { at giving birth }\end{array}$ & $\begin{array}{c}\text { Current } \\
\text { married status }\end{array}$ & $\begin{array}{c}\text { Current } \\
\text { occupation }\end{array}$ & $\begin{array}{c}\text { Birth } \\
\text { order }\end{array}$ \\
\hline $\begin{array}{c}\text { I was too shy to tell my family } \\
\text { because I was too young to } \\
\text { have a baby. }\end{array}$ & $16(2015)$ & Unmarried & Student & 1 \\
& $21(2014)$ & Married & Housewife & 1 \\
\hline I was too busy. & $20(2015)$ & Unmarried & Housewife & 2 \\
& $32(2010)$ & Married & Housewife & 4 \\
\hline My neighbors do just like that. & $26(1998)$ & Married & Housewife & 2 \\
\hline I was thinking. & $22(2014)$ & Married & Housewife & 1 \\
\hline
\end{tabular}




\section{Discussion}

\subsection{The Characteristics of Cabuynan}

In this study, $99 \%$ of subjects took ANC at least once during their pregnancy. While in the results from NDHS $2013,3.9 \%$ of pregnant women had never taken any ANC, $62.3 \%$ took 1 st $\mathrm{ANC}$ at recommended timing and $33.8 \%$ took it at late timing [2]. Comparing with the relative poverty prevalence $(31.0 \%)$ among families in Leyte province in 2015 [4], the poverty prevalence $(93.2 \%)$ in the study subjects was 3 times higher. According to the result more than $75 \%$ of women felt they faced some financial difficulties in daily life.

From the details above mentioned, compared with the average national level, it is considered that the women living in Cabuynan have a higher awareness of the ANC in spite of their poor living standards. The present results did not match with the previous studies that the ability of accessing to the health care services were influenced by the education level [6]. This is the one of outcome of many efforts made by hospitals and national/international GOs and/or NGOs for a long time. Still the fact remained that approximately $30 \%$ of women could not get the 1 st ANC within the first trimester which WHO recommended [3]. For that reason, the problem regarding the late 1st ANC is needed to be monitored properly. Solving this problem will contribute to the reduction of preventable deaths related to pregnancy there.

\subsection{The Factors Associated with Delayed 1st ANC}

Same as the previous study in Tennessee in the end of $20^{\text {th }}$ century, there were no significant differences in sociodemographic characteristics such as age, maternal education between the groups with different 1st ANC timing [11]. On the other hand, the income and the parity showed significant differences between the groups with different 1st ANC timing, similar to the previous studies [12], [13],[14]. However, no one answered the financial problem as the reason why they took their 1st ANC so late. In the Philippines, women can take their ANC without any payment, but they have to spend extra expenses for medicines or transportation fee same as in Uganda [15].

About the reason of the different parity, the more children they have, the more money they need to spend on their education and daily necessities. These results suggest the possibility that increasing their income may increase the capability to afford health related services and the aforementioned extra costs, as suggested in a previous study [16].

Secondly, the factors that made the delayed 1st ANC visit, despite the fact that multiparas were aware of their pregnancy earlier than primiparas, were the busyness for taking care of present children and the consequence of thinking about whether they will keep the baby or not (Table 5). The former reason matched with the result of previous studies. We did not ask directly about whether the pregnancy was intended or not, while the latter answer helped to infer that the pregnancy was accidentally happened. If so, this matched with the previous studies that the unwanted pregnancy caused delayed 1st ANC [17], [18]. At the same time, women who have many pregnancy experiences tend to think they have enough knowledge to take care of themselves. Normal pregnancy experiences also tend to give them strong confidence to take care of themselves, but such confidence has no basis and intervenes them to be aware of pregnancy related risks [15]. The confidence might give pregnant women little direct benefit from ANC and make them neglect ANC [19].

Thirdly, Gudayu found that the pregnant women who confirmed their pregnancy using urine test had around double chances to start their ANC within the first trimester of gestation period [20]. However, there was no significant difference in the use of urine pregnancy test between the 2 groups with different 1st ANC visit in this study. Looking at the reasons why they do not want to use it, almost all people felt it waste of the money because they have strong confidence to catch the signs of pregnant without urine test. Meanwhile some people spoke out that the reason of no use of urine test is fear they said that they couldn't understand or even imagine what it is and how to use it. The word 'test' reminded them something scary and consequently to give them right and useful knowledge is important.

Lastly, teenage pregnancy is considered risky for several reasons amongst becoming pregnant in school ages is riskier and can be one of the triggers for delayed ANC visiting. This trend is probably because of the longer education periods during when the people move to a bigger city which increases the chance of meeting prospective partners. Once they become pregnant, they don't want to make their parents being disappointed, so they try to keep it as a secret until parents will recognize it by the changes from their appearance.

\subsection{Recommendation}

To begin with, approximately $80 \%$ of women experienced being pregnant without graduating junior high school. If we considered the data from World Bank is the net enrolment rate for secondary school in 2013 both sex as $67.4 \%$, it might be expected that more than half of people in the Philippines will have a child without finishing secondary education [21]. This trend was also seen in the statistical data in Leyte province in 2015 which almost $40 \%$ of people didn't graduate from elementary school (table 1 [8]). Moreover, about half women consulted to their husband about extraordinary events during pregnancies. Then there was a tendency that they visited 1st ANC within 3 months of pregnancy period. The answer from the women who were aware of their pregnancy at the early stage and visited 1st ANC lately, pregnancy during school age is also the reason why they delayed taking 1 st ANC. In the Curriculum Guide by department of education, we could find many "physical health", "physical education" and "health" from the kindergarten, but rare for "sexual education", "sex education". The related terms of "sexual education" appeared in the section od "Growth and 
development / Personal health" in the grade 5 second quarter; Changes during puberty, Puberty-related health myths and misconceptions, Puberty-related health issues and concerns, Self -care and management of puberty-related health issues and concerns, Sex and gender. The more detailed information could be taught in "Family health" in grade 8; Gender and human sexuality, Teenage concerns, Development of decision, Dating, Courtship, and Marriage, Maternal health concerns, Responsible parenthood and so on [22]. From the above, sex education from early age must be given for student not only girls but also boys. In addition, it is also important to tell about sex education in a broad sense including how to use the pregnancy test, the importance of taking 1st ANC early in the gestation period. Next, more than $99 \%$ of women judged and noticed their pregnancy by amenorrhea. Nevertheless, the terms when they suspected being pregnant varied widely. Surprisingly, $15.7 \%$ of women judged a delay of menstruation 3 months or over behind the schedule. The later standard month of delayed menstruation for considering pregnancy was, the later the timing of the 1st ANC was. To consider the result that the women visit their 1st ANC after four months of gestation period because the neighbors do like that even they have already known their situation, it is essential to spread the right knowledge about determining pregnancy even with only one month of menstruation delay in communities [15], [16]. We expect that the Public Health Nurses and Barangay Heath Workers will take the role of this, and not only student but also out-of-school youth can reach the right knowledge even in the community.

\subsection{Limitation}

All the data in this study were based on interviews and it might involve recall bias. One more thing, we used opportunistic sampling, which cannot give any guarantee of representativeness. It is expected in the future study to use random sampling and the documented data designed sampling like cluster sampling and more objective data based on direct observation and/or clinical records. Even though, this was valuable as a first study to focus on the timing of the 1st ANC for promoting early visits in the Philippines.

\section{Conclusions}

Owing to the continuously efforts, women living in Cabuynan have a higher awareness of the ANC in spite of poor living conditions. Poverty and the number of pregnancies were suggested as the factors related to the delayed $1^{\text {st }}$ ANC. Increasing income and encouraging pregnancy women to consult their husbands are suggested as keys for making mothers visit their $1^{\text {st }}$ ANC during the recommended time.

\section{Acknowledgements}

I thank the research assistants for the devotion during the data collection and all the study participants for their kind cooperation.

\section{REFERENCES}

[1] WHO, UNICEF, UNFPA, World Bank Group and the United Nations Population Division, Trends in maternal mortality: 1990 to 2015. 2015.

[2] Philippine Statistics Authority and ICF International, "Philippines National Demographic and Health Survey 2013," p. 353, 2014.

[3] World Health Organization, "WHO Recommendation on Antenatal care for positive pregnancy experience," WHO Recomm. Antenatal care Posit. pregnancy Exp., p. 152, 2016.

[4] the Poverty and Human Development Statistics Division of the Philippine Statistics Authority (PSA), "2015 Full Year Official Poverty Statistics,” October 2016, pp. 1-42, 2015.

[5] Edgardo M. Gonzaga, M.D., "The SMACHS - EV Project Official Newsletter MACHI HEALTH NEWS," 2011. https://www.jica.go.jp/project/philippines/004/newsletter/in dex.html

[6] Mark Anthony, Mujer Quintos, "Trends in Regional Differences in Maternal Mortality in the philippines in the Last Four Decades," in International Conference on Research in Social Sciences, Humanities and Education (SSHE-2016), 2016, pp. 65-68.

[7] Philippine Statistics Authority. Population of Region VIII Eastern Visayas (Based on the 2015 Census of Population) [Internet]. 2016. Available from:

https://psa.gov.ph/content/population-region-viii-eastern-vi sayas-based-2015-census-population

[8] Philippine Statistics Authority. Leyte Quickstat [Internet]. 2017. Available from:

https://psa.gov.ph/content/leyte-quickstat-december-2017

[9] R. C. Team, "A language and environment for statistical computing." R Foundation for Statistical Computing, Vienna, Austria.

[10] Y. Kanda, "Investigation of the freely available easy-to-use software \&lsquo;EZR\&rsquo; for medical statistics," Bone Marrow Transplant., vol. 48, 2012.

[11] J. A. Gazmararian, T. L. Arrington, C. M. Bailey, K. S. Schwarz, and J. P. Koplan, "Prenatal care for low-income women enrolled in a managed-care organization," Obstet. Gynecol., vol. 94, no. 2, pp. 177-184, 1999.

[12] Manzi A, Munyaneza F, Mujawase F, Banamwana L, Sayinzoga F, Thomson DR, Ntaganira J, Hedt-Gauthier BL, "Assessing predictors of delayed antenatal care visits in Rwanda: a secondary analysis of Rwanda demographic and health survey 2010.," BMC Pregnancy Childbirth, vol. 14, p. 290, 2014.

[13] S. Agha and H. Tappis, "The timing of antenatal care initiation and the content of care in Sindh, Pakistan," BMC Pregnancy Childbirth, vol. 16, no. 1, p. 190, 2016.

[14] H. F. Molina, K. Nakamura, M. Kizuki, and K. Seino, "Reduction in inequality in antenatal-care use and persistence of inequality in skilled birth attendance in the 
Philippines from 1993 to 2008.," BMJ Open, vol. 3, p. e002507-, 2013.

[15] Kisuule I, Kaye DK, Najjuka F, Ssematimba SK, Arinda A, Nakitende G, Otim L, "Timing and reasons for coming late for the first antenatal care visit by pregnant women at Mulago hospital, Kampala Uganda.," BMC Pregnancy Childbirth, vol. 13, p. 121, 2013.

[16] F. Gebremeskel, Y. Dibaba, and B. Admassu, "Timing of First Antenatal Care Attendance and Associated Factors among Pregnant Women in Arba Minch Town and Arba Minch District, Gamo Gofa Zone, South Ethiopia," J. Environ. Public Health, vol. 2015, 2015.

[17] A. Exavery, A. M. Kanté, A. Hingora, G. Mbaruku, S. Pemba, and J. F. Phillips, "How mistimed and unwanted pregnancies affect timing of antenatal care initiation in three districts in Tanzania.," BMC Pregnancy Childbirth, vol. 13, p. 35, 2013.

[18] P. Mkandawire, "Gestational Age at First Antenatal Care
Visit in Malawi," Matern. Child Health J., vol. 19, pp. 23662374, 2015.

[19] L. Myer and A. Harrison, "B RIEF R EPORTS Why Do Women Seek Antenatal Care Late ? Perspectives From Rural South Africa," vol. 9523, no. 2, pp. 2-6, 2003.

[20] T. W. Gudayu, M. S. Woldeyohannes, and A. A. Abdo, "Timing and factors associated with first antenatal care booking among pregnant mothers in Gondar Town; North West Ethiopia," BMC Pregnancy Childbirth, vol. 14, p. 287, 2014.

[21] The World Bank, "Net enrolment rate, secondary, both sexes (\%)." https://data.worldbank.org/indicator/SE.SEC.NENR?locatio ns $=$ PH Accessed December 17, 2017

[22] Department of Education. $\mathrm{K}$ to 12 Curriculum Guide: HEALTH. 2016;(August):95. Available from: http://www.deped.gov.ph/sites/default/files/page/2016/Heal th CG_with tagged math equipment.pdf 